\title{
3
}

\section{Performance management for success: Public sector organisations in Australia and the Philippines}

\author{
Lewis Hawke
}

\section{Introduction}

I knew of John long before I met him. His 1992 book with Weller and O'Faircheallaigh was one of the first academic texts I had in my library on public sector reform. I had been inducted into public sector reform during a secondment in the UK with Her Majesty's Treasury in the mid1990s, where I was involved in managing and implementing some of the most innovative public management reforms at the time. When I returned to Australia, John had become well established as a gifted and insightful academic and commentator on the public sector, then based in Canberra. He seemed to be a regular fixture on television and was a very engaging speaker, able to present ideas and observations in a way both incisive and accessible to a diverse audience. By then, his works with Forster and Kelly (2000), and Jensen and de Vries (2003) has also become well established references for me.

I met John shortly after I had been involved in designing and implementing the accrual, outcomes and outputs budget framework for the Australian Government. His voracious interest and infectious enthusiasm for 
knowledge about the initiative was a rare and welcome experience. Until I met John, I had found it uncommon for academics to take such a strong interest in every aspect of public policy, including the arcane technical and operational elements. He helped to broaden my perspective on the multiple dimensions of public policy, from the mostly technical and theoretical aspects that I had previously focused on, to the political, historical and sociological. During the process of preparing our joint contribution to the volume The Reality of Budgetary Reform in OECD Nations: Trajectories and Consequences (2010), I developed a great respect for his incredible productive output. His ability to orchestrate the work from discussion of the micro-level details of our chapter to the macrolevel themes and content of the whole book with Jensen, de Vries and other contributors was most impressive. His insights on the significance of politics, history, public policy and management and how they shaped public finance and economic outcomes has guided my approach to public sector reform since then.

My most enduring memory of meetings with John was a dinner we had with John Halligan and Allen Schick at my home in Canberra. My wife, Carol Kiernan, had done the hard work of putting together a menu that met everyone's needs, while I had the delight of sharing ideas on public sector reform with three of the most experienced and celebrated brains in the business. At the time I had just started thinking about my PhD on public sector performance under the sage guidance of John Halligan, so the ideas forming the germ of the paper below were high on my agenda for discussion. I have no doubt that the influences of all who attended that dinner have shaped my subsequent research. John Wanna's encouragement and his vibrant approach to enquiry and analysis continues to guide and motivate my work in this field.

\section{Context}

The use of public sector performance management and budgeting has expanded from a small group of early adopters in the 1960s and 1970s to a wide range of countries across all continents and income groups (Moynihan and Beazley 2016). Some valuable early work on performance management in Australia emerged from Griffith University (Wanna, O'Faircheallaigh and Weller 1999; Wanna, Forster and Kelly 2003). Ironically, much of the literature on public sector performance practices 
documents the underachievement of the approach and the various attempts to modify and address the symptoms of unrealised goals. This paper takes an optimistic perspective to public sector performance, seeking to determine common success factors for the practice that would offer a pathway to better outcomes for all users.

The research for this paper draws from the growing body of literature to establish a broadly applicable framework for systematically analysing and addressing the common, fundamental challenges and success factors for public sector performance management. This paper focuses on the organisational level rather than the system-wide approach prevalent in the literature. There are two main reasons for concentrating on organisations. Firstly, the literature indicates that the organisational level is where public sector performance management is likely to have the greatest impact and potential value (Moynihan and Pandey 2010). Secondly, experience within and across countries demonstrates that the organisational level is characterised by considerable diversity in the results achieved from adopting performance-based arrangements (De Waal 2010; Taylor 2011). These observations suggest that analysis of the opportunities for improving performance management may be more fertile at the organisational level than by tinkering with the broader system settings (Hawke and Wanna 2010; Hawke 2012).

The first step on the path to establishing an analytical framework is to develop a basic hypothesis and apply it to real-world practices to test its relevance. The paper firstly explains how the core influences on public sector performance management have been distilled from the literature. The methodology for testing the framework is then outlined, along with an explanation of the approach to data collection. The results of the survey are summarised in the third section of the paper, focusing on whether there is support for the hypotheses underpinning the framework. Finally, the limitations, implications, conclusions and directions for further work are discussed.

The data used in this study were obtained using a survey of central government organisations in Australia and the Philippines. Both countries were among the early adopter group for performance management around four decades ago and therefore have considerable experience in the application and adaptation of the practices (Hawke and Wanna 2010; Venner 2019). 
Despite similarity in the extensive gestation period for performance management in both countries, the two countries selected are quite different in their economic and social circumstances, institutional and political arrangements, cultural heritage and many other important respects. These differences offer the opportunity to test the accuracy and relevance of the hypothesis across national as well as organisational boundaries. They also provide a basis for identifying characteristics that may have a greater or smaller influence on success in performance management for individual organisations in both countries.

\section{Theoretical framework and hypothesis}

In preparing for the literature review for this study, it was essential to set boundaries to limit the scope to a manageable range. One aspect of boundary-setting involved defining the key elements. The main elements that warrant definition are captured in the title of this paper, specifically: 'performance management', 'public sector', 'organisation' and 'success'.

This study adopts Australia's Management Advisory Committee's (MAC 2001, 14) definition of performance management as, 'interrelated strategies and activities to improve performance of individuals, teams and organisations. Its purpose is to enhance the achievements of agency goals and outcomes for government'. The public sector refers to the International Monetary Fund's Government Finance Statistics Manual definition, as that which contains all units controlled directly or indirectly by government (IMF 2014). Organisation is used as an umbrella term in this study to refer to a body with an explicit form, responsibility and authority bestowed on it by government. Organisations can include bodies described as ministries, departments, agencies, corporations, cooperatives, entities, service delivery units, associations and authorities, among other terms used in government. Success is defined as the achievement of some or all of the goals and objectives set for performance management practices. The goals and objectives that are considered important for this study are whether performance management contributes to better quality performance information, if performance information is used by public sector stakeholders, and whether it causes or contributes to positive changes within the organisation or the matters for which it has authority and responsibility. 
The literature search was structured using the defined terms, focusing primarily on research with the highest relevance and citation frequency during the last two decades. Where possible, existing literature review articles were used to limit the search (Talbot 2010; Hawke 2012; Gao 2015; Kroll 2015a, 2015b; among others).

One important aspect missing from many academic studies is an examination of the practitioner literature that has emerged from governments and international institutions during the period under review. This was a feature of John Wanna's body of work on public financial management, which was particularly notable for his pairing of academics and practitioners in the international comparative volumes, for example, Controlling Public Expenditure (Wanna, Jensen and de Vries 2003) and The Reality of Budgetary Reform in OECD Nations (Wanna, Jensen and de Vries 2010). The practitioner literature is important because it provides details on a more extensive range of applications and the lessons learned by the institutions and governments involved. Other published and unpublished works outside the conventional realm of public management literature and the time period for the main review have been examined where they have demonstrated high relevance and are empirically robust.

The literature review performed for this study has identified six broad categories of factors influencing public sector performance management. These factors are: external, institutional and structural, leadership and management, technical capability, organisational culture and behavioural. Other factors have been considered by researchers but generally found to have minimal or inconsistent direct influence on success, such as the size and type of organisation. While those factors have sometimes been linked to one or more of the six core factors, for example through issues such as span of control and complexity (Bohte and Meier 2001), they have not been found to be important per se for the success of performance management. The precise definitions and boundaries of the six groups of influences can be debated, but at this stage of development, it is considered more important to recognise the nature and significance of their individual and joint influences than develop a detailed taxonomy. There will be ample opportunity for refinement when, or if, their importance is confirmed and when systematic research on their influence becomes more prevalent. 


\section{(a) External influences}

These influences are, by definition, actions or events that are exerted from outside organisations. They can come from elsewhere in the public sector, from other parts of the jurisdiction or from foreign sources. External influences can be positive, negative, transformative or reinforcing. A prominent external influence identified in the literature comes from the political sphere, sometimes through embedded political appointments in organisations, and more broadly through policies and practices that the organisations are obliged to implement. The potential significant effects of political economy on the efficient and effective functioning of government has been a feature of practitioner literature for at least a decade (Fritz, Verhoeven and Avenia 2017). In some instances, shifts in political power have resulted in major changes to the performance management arrangements (Hood 2006) while, in others, they have maintained and reinforced the basic approach applied by predecessors (Hawke 2012; Venner 2019).

Economic and social change have been identified as another subgroup of external influences on performance management. Strong economic downturns with contractionary fiscal consequences have been shown to displace evidence-based policy refinements and reallocations with arbitrary sectoral or across-the-board expenditure cuts (Schick 2014). The displacement of performance-based approaches by subjective cuts is often a temporary feature to deal with urgent, short-term macro-fiscal concerns and reverts to the previous approach once the latter concerns have been addressed.

External pressures have been identified as providing a catalyst or tipping point for the introduction or substantial change in performance management arrangements (Moynihan and Beazley 2016). In newer adopters of performance management methods, this can be isomorphic, in an attempt to achieve benefits claimed by other adopters (Mussari et al. 2016) or in response to weaknesses identified by critics of existing models within countries.

The separate and complementary roles of parliament and state audit has been examined in many studies. Key findings include the observation that, where either or both institutions are actively and positively engaged in performance monitoring and review, the results are significantly 
better than in those where little or no interest is shown in efficiency and effectiveness issues. Results are also weaker where the institutions are not well connected in their oversight (Santiso 2015).

Many authors have noted the importance of a strong central finance organisation in establishing and maintaining effective performance management arrangements (e.g. Wanna, Forster and Kelly 2000; Wanna, Jensen and de Vries 2003). Central organisations are seen to have an important role in setting and policing the procedures that must be followed, as well as providing guidance and capacity building needed by other organisations. It is common for central organisations to exert an accountability or challenge role to ensure rigorous and reliable use of performance information within the government system.

The role of public participation and citizen engagement has been seen as an area of external influence that is increasing in significance as trust in government has receded. It has not been identified as having a major influence on performance management for individual organisations or at the system level to date, except where local community interest is strong and their views are effectively channelled into the policymaking process (Moreno and Garza 2015).

\section{(b) Institutional and structural influences}

This group of influences includes the legal and regulatory framework in which organisations are established and the formal public sector environment in which they operate. The roles and responsibilities, organisational composition and interrelationships with other organisations all serve to fix an organisation within a symbiotic organism of government. Each organisation has its place in the organism and is affected by other parts to a greater or lesser extent. The structures within this group of influences may be internal or external to the legal boundaries of the organisation but still part of its operations, for example in relation to other organisations within a sector or policy grouping, subsidiary entities or regional bodies.

Institutional and structural influences are distinguished from external and managerial influences because they involve actions directly affecting the organisation as a result of institutions exerting powers that they have attained, either by law or convention, within the organism of government. This includes the extent to which organisations have autonomy to perform 
the functions and responsibilities expected of them, and the degree of control and rigidity imposed on the organisation from the other parts of the government organism.

Structure within organisations is an important part of this group of influences. Nicholl (2006) highlighted the stark difference in governance and performance outcomes between the well-structured central bank and other government structures within the newly established state of Bosnia-Herzegovina. Bohte and Meier (2001) identified significant differences between performance outcomes as a result of differences in span of control among educational organisations in Texas, where the roles and functions of the organisations were otherwise quite similar. Structure can be a negative or complicating influence on performance where the organisation's operations are not effectively aligned with performance goals, and vice versa. It increases transaction costs required to achieve joint responsibilities, allows for confusion or dilution of accountability and reduces efficiency.

\section{(c) Leadership and management influences}

Leadership and management influences are the most reported and analysed of all six groups within the academic literature. The linkage between new public management and performance measurement in the 1990s and 2000s was a strong theme in the literature. More recently, the focus has moved from principal agent issues to the role of leaders and managers in setting the performance agenda and driving better results either directly or indirectly through their actions, engagement and encouragement (Moynihan and Pandey 2010; Dull 2008). Leaders are seen as those within organisations who initiate or catalyse change and transformation, while managers are considered to be instrumental in implementing change and maintaining direction and momentum.

Leadership and management can have positive and negative influences, as is true for all six groups. The absence of performance-supportive leadership and management has been shown to be a major impediment to effective change, through various techniques such as passive resistance at one end of the scale, or active gaming at the other. Some writers have identified important subtleties in the use of leadership and management to facilitate change. Engagement in routine dialogue on performance and 
change with staff has been shown as a positive influence (Moynihan and Pandey 2010), while more heavy-handed monitoring and control has been shown to have a detrimental effect (Rasul, Rogger and Williams 2018).

\section{(d) Technical influences}

Technical influences encompass the rules, procedures, requirements, specifications and limitations on performance management arrangements. This group also includes the systems, practices, skills, resources and capabilities for implementation, management and maintenance of the schemes. It occupies the largest seam of literature among practitioners - from system design, best practices and refinements, to lessons learned and comparative analysis (Wanna, Jensen and de Vries 2010; OECD 2018, 2019).

Within this theme there is an ongoing tension between those who see performance information as a tool for allocating budgets, and those who see it as an input for informing budget and policy decisions. Others see it as separate from budgeting, as a vehicle for improving services, accountability for achieving targets or alignment with policies and strategic objectives. Behn (2003) identified eight different purposes for performance information: to evaluate, control, budget, motivate, promote, celebrate, learn and improve. His advice was to be clear about the purpose(s), which would then help to design the architecture to go with it. While the advice appears clear and simple, the technical application has proved to be more challenging.

One reason for the relatively large share of practitioner literature devoted to technical issues is that they have proved to be very difficult, if not intractable (Wanna et al. 2010). Measurement of performance has been a challenge for practitioners for more than 40 years in some countries, particularly in relation to the identification, measurement and attribution of outcomes. Complexity has been another challenge, where getting the right balance of the number and importance of performance measures, and methods of performance assessment, appears to be more of an art than a science. There has been a general trend among longer-serving practitioners to reduce the number of performance indicators that are regularly reported. It is not clear whether this has contributed significantly to better results from performance management (OECD 2019; Moynihan and Beazley 2016). 
Monitoring of performance management practices by state audit agencies has demonstrated that there are substantial differences between the success of organisations in the application and use of arrangements in their respective national and subnational governments. This is often attributed to inadequate compliance, weak internal processes and procedures, low implementation capacity or other technical aspects, as evident in published performance audit reports by state audit institutions in the UK, Canada, Australia, New Zealand, the US and elsewhere.

Countries that have changed their performance management arrangements, often multiple times over the decades of implementation, have sought to resolve technical weaknesses with varying degrees of success (Moynihan and Beazley 2016; Curristine and Flynn 2013).

\section{(e) Cultural influences}

Cultural influences encompass norms, modes of operation, communications, understandings and tacit routines. Woolcock $(2014,16)$ describes them as the 'use of symbols, frames and narratives connecting structure and agency'. Reformers in government seek to embed a 'performance culture' in which all agents see the importance of performance information and use it to enhance organisational achievements. Schick (2014) noted that there is a dark side of culture as well. He referred to culture as 'obdurate' and able to withstand waves of reform pressure.

Organisational culture provides a subliminal means for navigating the unknown, unfamiliar or uncomfortable in the company of others who share it. Where it is aligned with performance objectives, it can be effective in overcoming the challenges of disappointing results or inconvenient outcomes. Where culture is not aligned with performance objectives, it can be a source of resistance, opposition and ultimately failure of systems altogether.

Moynihan and Pandey (2010) and others have postulated a link between leadership and culture, through which leaders can steer culture to a more benign or positive association with new approaches. It can be a fickle link, however, if those being led are not convinced by the leaders' apparent commitment (Dull 2008). 
People who work in the public sector are considered to have a more supportive attitude to their organisations and stronger commitment to its goals, rather than the more utilitarian and contractual association attributed to private sector organisations. Some researchers have observed that where systems or organisations have taken a more contractual and incentive-based approach to public services, the responses of staff have changed the organisation in ways that are less communal and more individualistic (Rasul, Rogger and Williams 2018).

\section{(f) Behavioural influences}

Performance management, and more often performance budgeting, has been found to have a strong interrelationship with behaviour. A common justification for introducing performance management practices has been to provide stronger incentives and signals to organisations and their staff about the expectations on their behaviour, productivity and satisfaction (Department of Finance 2016; Department of Budget and Management 2016). It is argued that clear goals and targets will focus the minds of staff and managers on what is important and improve the efficiency and effectiveness with which it is achieved.

Paradoxically, it has been shown that where goals and targets are tightly prescribed, and incentives or sanctions are strong, performancebased initiatives can have perverse effects through gaming, cheating or misinformation. The literature abounds with examples of perverse behaviours resulting from poorly implemented performance management arrangements (Radin 2006; Hood 2012). Short of corrupt or fraudulent practices, it is also argued that the perverse effects can be ameliorated or eliminated by more effective oversight, increased dialogue and building trust with organisations to address the source of behavioural dissonance.

\section{(g) Denouement}

The six groups of influences outlined above are strongly represented in the literature, either individually or in various combinations. The interrelationship between them, and even potential overlap, is evident such as at the boundary of external and institutional influence, or the interaction between leadership, culture and behaviour. More important for this study is that the main strands of performance management literature do not identify any other significant influences on performance management outside one or more of those groups. Thus the central 
hypothesis to be tested by this study is whether the six elements identified above are the only influences on performance management in public sector organisations. The remainder of this paper seeks to put this hypothesis to the test and to assess how those or other influences are manifest in the Australian and Philippine central government organisations.

\section{Methodology}

In the absence of suitable existing data on this topic, it was necessary to collect sufficient new data to allow for reasonable assessments to be made about the influences on performance management and how they affect the quality and use of performance information. The study sought to obtain the maximum number of observations on public sector entities within the two countries chosen using an ethically appropriate methodology. The study was initially discussed with central budget departments in both countries, which are responsible for performance management arrangements, to seek their agreement for the study to be performed, though not necessarily seeking their endorsement of it.

In both countries the central budget departments made first contact with potential participants to inform them about the study. They requested that any organisation willing to participate should respond to them, and only then would their contact details be provided to the researcher. One reason for seeking clearance for data collection with policy departments was to reassure participants that the process was neutral in relation to existing policies of government and responsible agencies. This aimed to avoid reticence or defensive behaviour in responding to the survey, which might otherwise be expected from public sector organisations responding to requests from an un-vetted external analyst. Self-nominating organisations were contacted by the researcher if they responded positively to the central agencies.

The survey adopted a structured approach involving a carefully designed questionnaire combined with follow-up interviews to confirm responses and obtain supplementary information on each organisation. The questionnaire and interviews were targeted to the person and position in each organisation with primary responsibility for administration and oversight of the performance management arrangements. 
The questionnaire was designed using mainly multiple-choice questions, applying various response techniques to solicit accurate and unbiased responses but primarily using adaptations of the Likert five-point scale. Many questions included an 'other' option to avoid unduly limiting the scope for answers. This was considered to be particularly important in relation to the main research questions where the existence and significance of other influences on performance management was crucial to the study. It was also important in areas where a comprehensive list of possible options was not practical or realistic, for example, results achieved, challenges experienced and procedures adopted.

The length and complexity of the questionnaire sought to balance the desire for as much information as possible from the maximum number of respondents with the need to achieve the maximum number of fully completed questionnaires. The intended result appears to have been successful because more than 90 per cent of people who volunteered to undertake the survey completed all questions. Most of those who completed the questionnaire were also willing to be contacted for faceto-face interviews, indicating that they were not deterred from further participation by the content, length or complexity of the questionnaire.

The questionnaire sought to obtain data that were relevant to the essential research questions in addition to other useful information gathered in previous surveys on performance management by other researchers. This broader focus allowed the study to obtain useful contextual data and provide an additional test of the credibility and reliability of results, to the extent they were consistent with the findings of other studies, while also taking account of important differences. The sources of relevant work on countrywide practices included the International Monetary Fund (Robinson and Brumby 2005) survey of performance budgeting and management in 16 developing countries and the Organisation for Economic Cooperation and Development's (OECD) Government at a Glance (2011 to 2017) survey, which covered aspects of structural, institutional and technical matters. Moynihan and Pandey's (2010) survey of individual managers gathered data on other relevant issues, including incentives, behaviour and organisational culture, but adopted a more quantitative approach that was not completely suited to the current study.

The format for the questionnaire included identification of defining characteristics of the organisation and the characteristics of performance management arrangements. Approximately 75 per cent of the 
questionnaire examined the six influences on design, implementation, utilisation and impact of performance management. The questionnaire ended with three open questions seeking general impressions on the strengths and weaknesses of performance management and suggestions for improvement. The questions were mostly the same for both countries except where terminology, policy and institutional differences warranted some adaptation. Interview candidates were selected after the questionnaires closed based on their willingness, their accessibility and the desire to achieve a balance in the characteristics of organisations and their performance management experiences.

In Australia, two phases of the survey were performed: one in 2012 and the second in 2019. One reason for undertaking two surveys was to consider potential differences over time. It was also of interest to examine whether the major change of performance management policies and practices after the survey in 2012 had a material impact on the significance of different influences.

The main change in performance management policy and practice in Australia between the two phases of the survey was the enactment of the Public Governance, Performance and Accountability Act 2013 (Cth) (PGPA Act). This legislation combined the coverage of previous public entity laws and established for the first time legal obligations to prepare performance plans and report performance results. The PGPA covered all national government entities and was accompanied by extensive guidance from the Department of Finance (DOF) and scrutiny by the Australian National Audit Office.

Only one phase of the survey is being conducted in the Philippines, in 2019, coinciding with the timing of the second Australian phase.

\section{Main findings}

The questionnaires in both countries garnered responses from approximately 20 per cent of the total number of organisations subject to performance management practices. The responses contained a suitable cross-section of sizes, types and functions of organisations within each country, as summarised in Figures 3.1 and 3.2. 
3. PERFORMANCE MANAGEMENT FOR SUCCESS

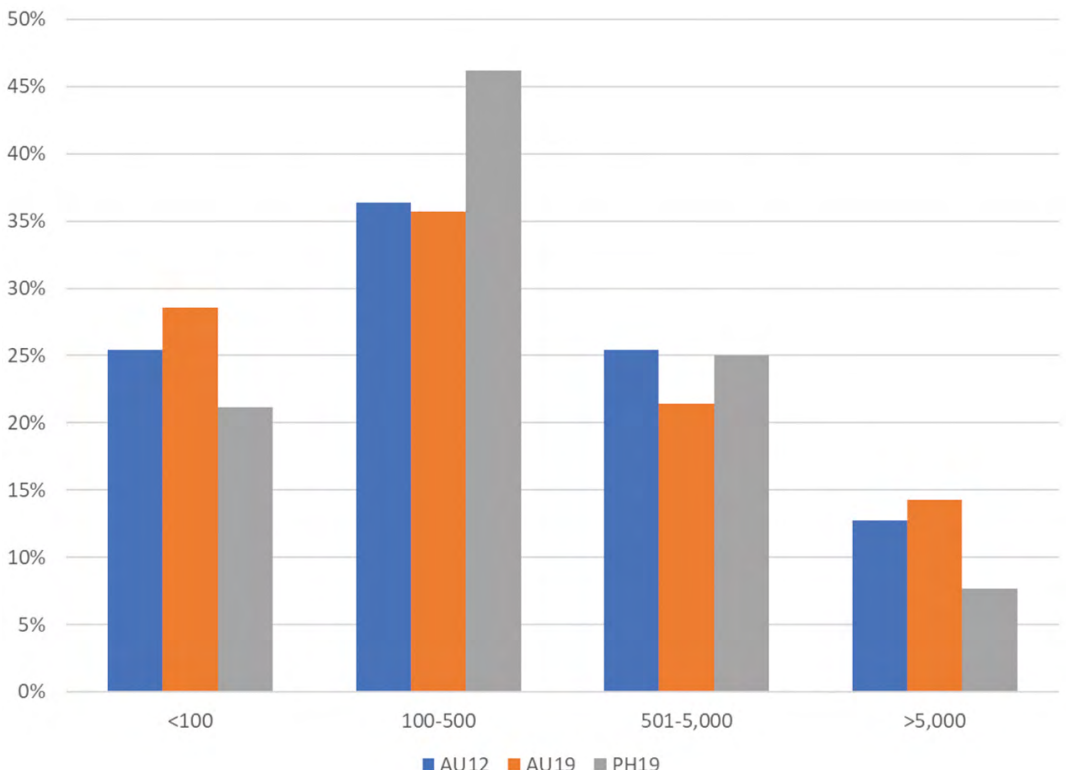

$90 \%$

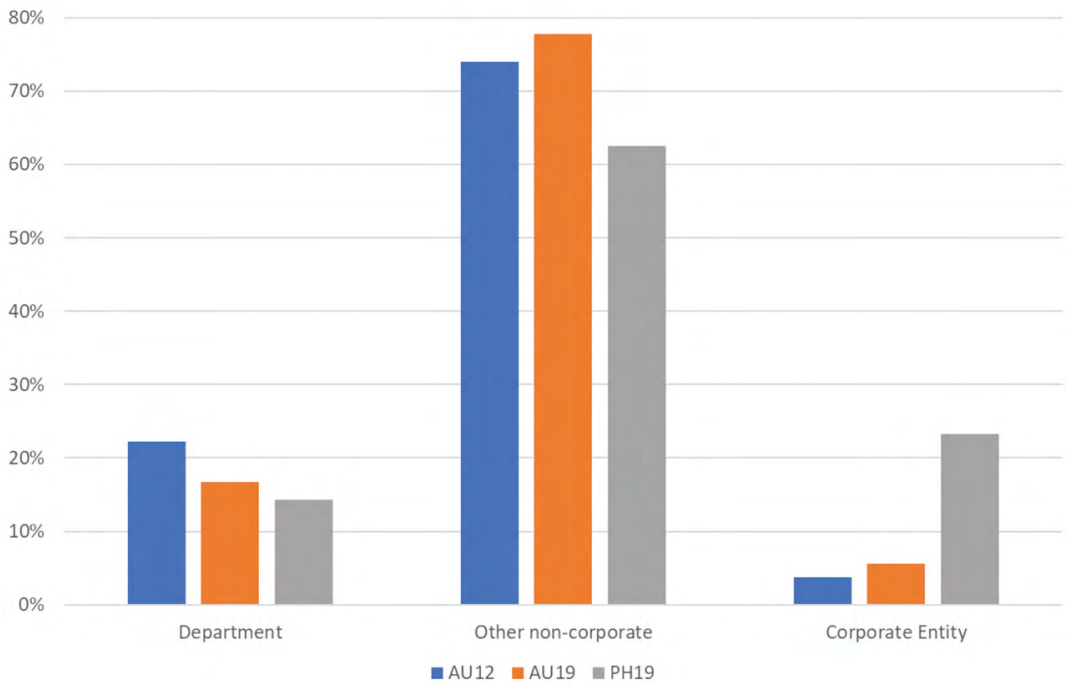

Figures 3.1 and 3.2. Organisation size and types (\% of respondents).

Source: Author's summary of study results. 
The first phase of the Australian study (AU12) obtained completed survey responses from 49 organisations. The second Australian phase (AU19) has produced 16 completed responses to date, but more are anticipated from a second round of invitations. Even though the number of respondents to the second phase so far is smaller than the first phase, it includes a sound cross-section of organisations, most of which are the same or include functions performed by participants in the first phase.

The proportion of organisation types and sizes that have participated in the survey reflect a similar pattern to the sizes and types across the total population of organisations in both Australia and the Philippines. The remainder of this paper draws on results from one or both phases of the Australian study to illustrate various characteristics in the simplest and clearest way. Both sets of results are presented where there are significantly different findings between the two phases.

The Philippine survey (PH19) yielded completed responses from 57 organisations. The coverage included government departments, public enterprises, educational institutions, service delivery agencies and regulatory bodies of various sizes. The areas of responsibility covered most sectors of public responsibility including finance, budget, education, transportation, law enforcement, environment and regional administration.

Both countries have applied performance management in the public sector for more than three decades, so the arrangements in place incorporate many of the common features used in other countries, as reported by the OECD (2019). Figure 3.3 shows that performance information is collected at multiple levels within organisations, primarily at the whole organisation level. Both countries produce published performance reports incorporating performance indicators and evaluation findings. Most organisations link their performance information to organisational strategy and goals, particularly in the Philippines. Both countries require regular review and audit of performance information. 


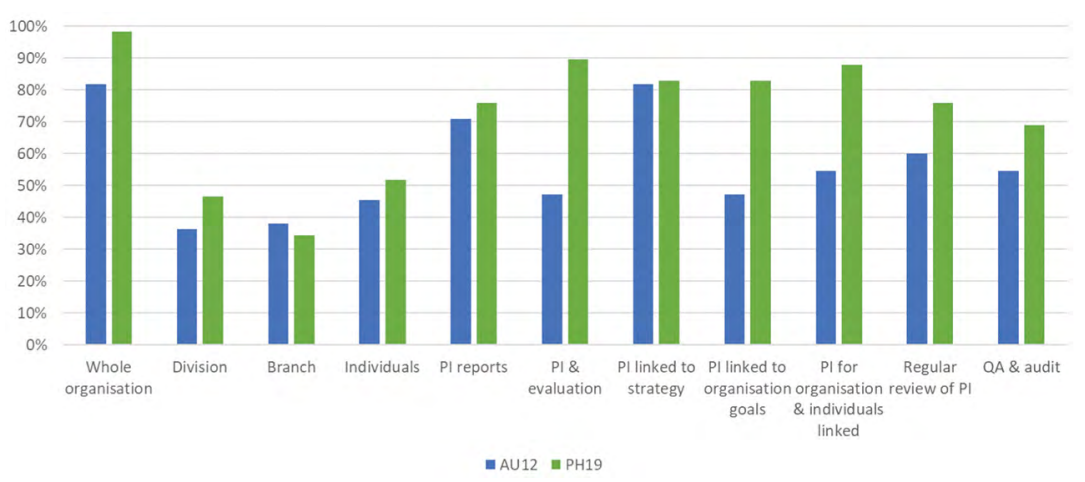

Figure 3.3. Organisational performance management attributes.

Source: Author's summary of study results.

The pervasiveness of performance management attributes in both countries offers benefits and challenges for this study. The benefits are that they provide positive examples of countries where performance is embedded in organisational management and operations so they are most likely to exhibit robust findings on performance management practices. The challenge arises from the same attribute, which means that weaknesses and major differences in performance measurement are less likely to be apparent than between countries with more diverse performance management trajectories.

The headline result of the study is that both countries have identified all six elements presented in the hypothesis as important influences on the success of performance management, as measured by quality and use of performance information. Figure 3.4 summarises the responses from both countries, including the two phases of the Australian study.

The results indicate that the Philippine organisations consider all six elements to be strong influences, with slightly more important influences provided by institutional and structural factors and leadership and management than the other four elements. Australian organisations considered that leadership and management was the most important influence in both phases of the survey. Cultural and technical aspects were considered the next most important in both phases and both of those elements appeared to be more important in the recent Australian phase than in the earlier phase. 


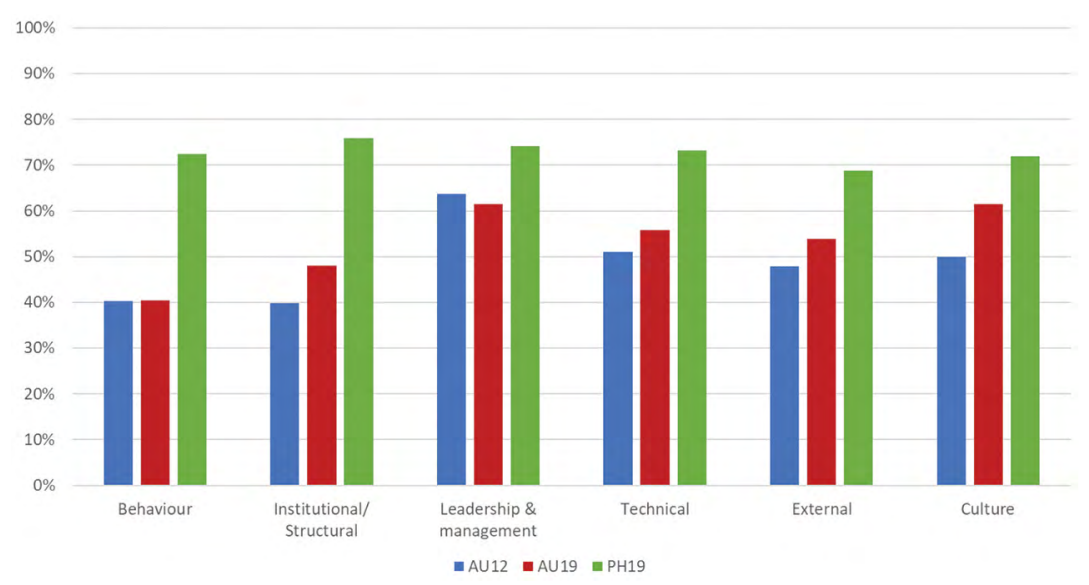

Figure 3.4. Identified influences on performance management ( 0 = weak, 100 = strong).

Source: Author's summary of study results.

Figure 3.4 does not include information on other influences because no organisation in either country considered that any other factors were important, despite specific questions in the questionnaire and interviews prompting suggestions for other influences. This may be because the six specific influences identified can be interpreted quite broadly, but even so, it provides an encouraging endorsement of the hypothesis. The remainder of this paper seeks to explain and discuss how the six elements have contributed to performance management success within public sector organisations in both countries.

\section{Discussion}

Before examining the contributions of individual influences, it is important to provide a foundation and context for the analysis in terms of whether performance management achieved any success at the organisational level in either or both countries covered by the research. The survey included several specific questions relating to the quality of performance information, the challenges faced in achieving good quality performance, the use of performance information, the effects of performance information and their impact on aspects of performance commonly claimed by proponents to be directly related to performance management. 


\section{(a) Quality of performance information}

Quality of performance information was assessed in this study using a commonly adopted checklist referred to as 'SMART': specific, measurable, achievable, relevant and timed. Although the criteria used in the acronym may vary among countries the intent is generally the same. The countries using this acronymic model consider that performance information that rates highly on all of the criteria is more useful and robust than that which do not. Respondents to the Australian and Philippine questionnaires scored themselves above the mid-range against all of the SMART criteria, though 'measurability' was considered to be more of a challenge to the 2012 Australia respondents and 'timed' indicators were more challenging for 2019 Australian respondents. The Philippine respondents scored themselves higher on all attributes than Australians, possibly reflecting an 'optimism bias' for each criterion, but the differences between criteria are notable. They considered that they were particularly strong on the 'relevance' and 'specificity' of their information. 'Measurability' was the weakest for Philippine organisations, but still averaged more than 70 per cent of the maximum score, as shown in Figure 3.5.

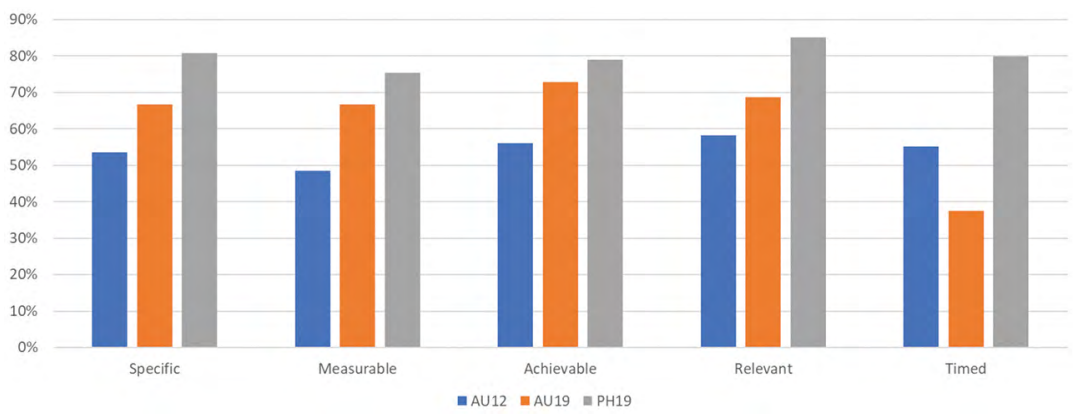

Figure 3.5. Quality of performance information ( $0=$ weak, $100=$ strong). Source: Author's summary of study results.

\section{(b) Use of performance information}

Philippine questionnaire respondents identified substantial usage of performance information by organisational management, as shown in Figure 3.6. This included politically appointed secretaries and chief executives of public sector organisations who are responsible for the management and operations in those bodies. Politically appointed 
ministers in Australia were identified as only moderate users of performance information and other elected officials reportedly showed little interest. In Australia, operational unit managers and senior management were the main users of performance information but both groups of managers showed less interest than their Philippine counterparts. This is consistent with research and analysis on Australia by Wanna and others (Wanna and Podger 2017). This may reflect an important difference between Australia and the Philippines in how performance information is used. The Philippines Government provides financial incentives at organisational and individual levels for excellent performance, sometimes more than 15 per cent of salary, so there is a stronger personal motivation for internal management to focus on organisational performance.

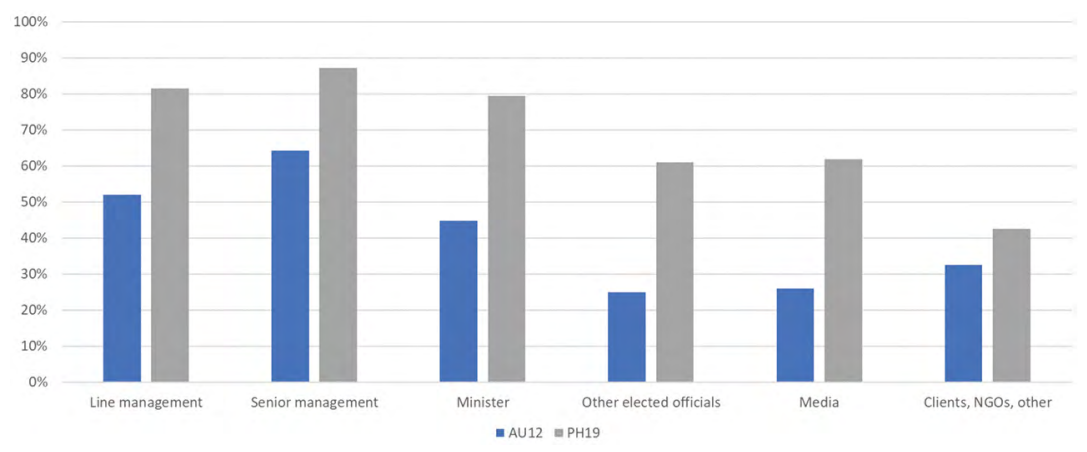

Figure 3.6. Users of performance information $(0=$ not at all, $100=$ extensively).

Source: Author's summary of study results.

The greater interest in performance information in the Philippines appears to have translated into greater use of the data, as shown in Figure 3.7. According to respondents, the use of performance information directly contributed to refinement of processes, improvement of service design and quality, and development of budgets and policy. The Philippines' use of performance information was reportedly more extensive in all areas than Australia. The relatively low use of performance information in policy development and design in both countries compared with its use for other activities suggests a strong emphasis on annual performance indicators and less use of broad program and policy evaluation, which is more often associated with policy development and advice (Wanna, O'Faircheallaigh and Weller 1999). 


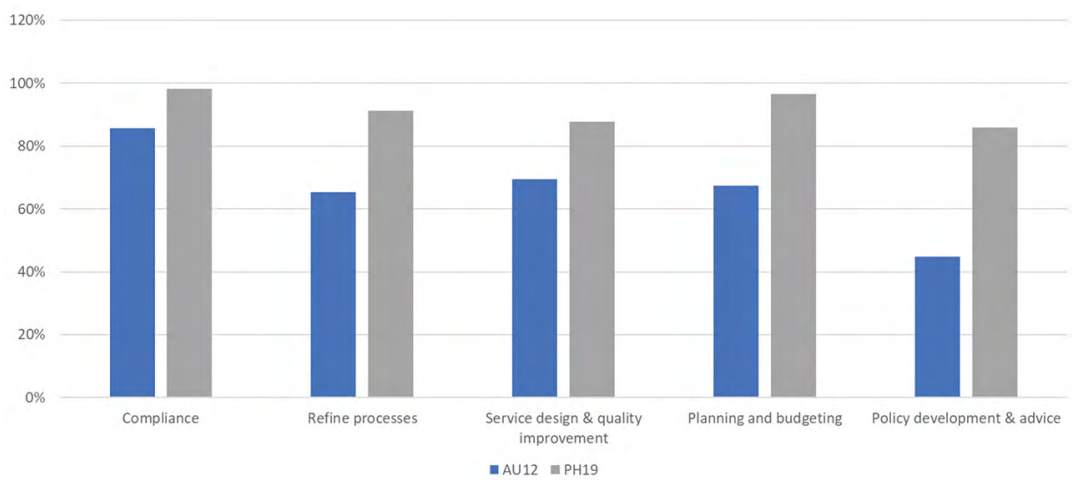

Figure 3.7. Uses of performance information $(0=$ not used, $100=$ extensive use).

Source: Author's summary of study results.

Even in Australia, however, there was a high positive correlation between the level of use and the application of performance information for operational improvements. For example, the correlation coefficient between operational management use of performance information and process refinement was 0.67 . The correlation coefficient between operational management and service quality improvement was 0.75 and with planning and budgeting it was 0.64 . Similar correlation was found with operational improvements and senior management use of performance information. While the accuracy of correlation-using ratings data can be unreliable from a strict statistical perspective, it provides an indication that the relationships are at least consistent with expectations.

\section{(c) Effects and impact of performance information}

Australian and Philippine respondents reported that the use of performance information also resulted in systemic organisational benefits, as summarised in Figure 3.8. The most significant impacts in both countries were greater employee focus on results, more accountability, improvement in service quality, improved information for decisions and better budget allocation. Smaller impacts were reported in relation to efficiency improvements, communications and external relationships in both countries. In all categories of impact, Philippine organisations reported more extensive use than Australia, which could indicate an optimism bias in their self-reported achievements, as mentioned previously. This will be scrutinised carefully in completing the interview process to see if the actual changes reported are stronger or simply interpreted differently by the respondents. 


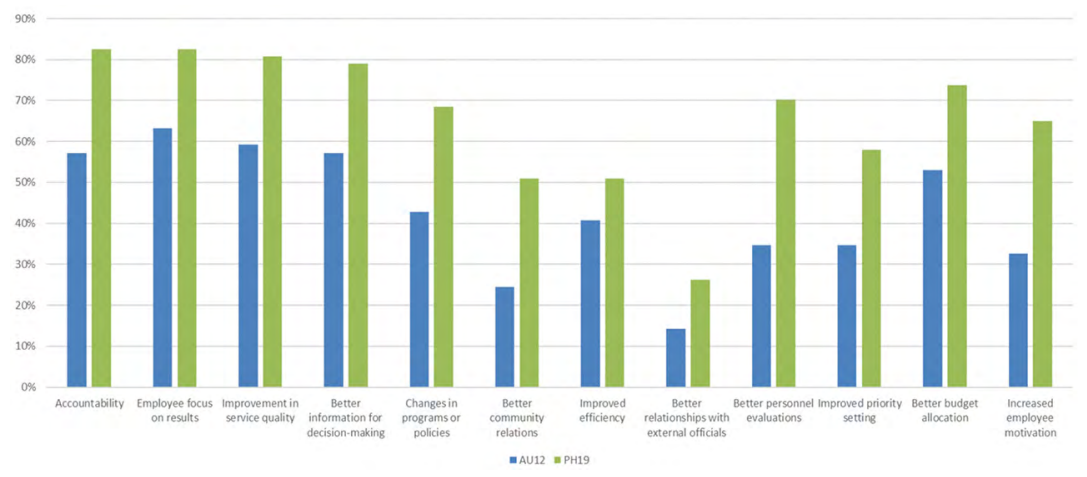

Figure 3.8. Effects and impact of performance management ( $0=$ no effect/impact, $100=$ extensive effect/impact).

Source: Author's summary of study results.

In summary, respondents in both countries reported strong performance in terms of quality, use and impact of performance management. Even allowing for a generous margin of optimism bias that can be expected from self-reported results, the overall conclusion of respondents in both countries is that performance management has achieved significant benefits. The question of what has influenced the achievement of such positive results is addressed in the remainder of this section.

\section{(d) External influences}

Survey participants were asked about seven external influences commonly noted in the literature. These included political, economic and customerrelated factors in addition to economic and fiscal conditions, comparison with other organisations, and actions by other public sector bodies that had implications for their performance. As illustrated in Figure 3.9, Australian respondents identified political and client-related factors as the main external influences with economic and fiscal conditions and other public sector bodies as important factors. Australian respondents were less concerned about the media and comparisons with other organisations.

The aggregated responses from Philippine organisations rated clients and media as most important. This was partly due to the importance of those groups to many of the state universities and colleges, which made up about one-quarter of the Philippine respondents. Other Philippine respondents identified political factors, especially from parliament, other public sector bodies and economic and fiscal conditions as major external influences. Philippine respondents also reported little influence from comparisons with other organisations domestically or internationally. 


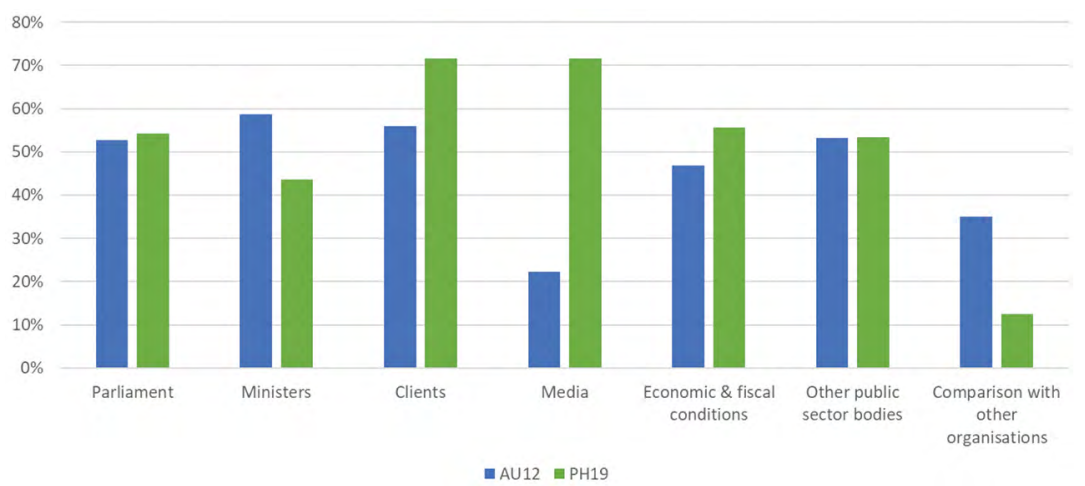

Figure 3.9. External influences on organisational performance management.

Source: Author's summary of study results.

The other public sector bodies referred to by respondents are primarily the central budget departments and state audit institutions in each country. The central budget departments are responsible for public sector performance policy development and implementation. Both countries have powerful central budget departments that closely supervise the implementation of budget policy, primarily through the annual budget process, but also through issuance of circulars requiring action by budgetdependent organisations. The state audit institutions in both countries have wide remits covering the financial and non-financial practices and performance by central government organisations.

\section{(e) Institutional and structural influences}

Institutional and structural factors control the form, scope and framework in which performance management operates. They have a direct effect, through determination of what is required from organisations, such as the form, content and frequency of reporting on performance. They also have an indirect effect by excluding or limiting what is not permitted, or what is more difficult because it requires management across structural boundaries where accountability and responsibility become blurred or more complex. Survey respondents identified five institutional and structural aspects that were important influences on performance management, as summarised in Figure 3.10. 


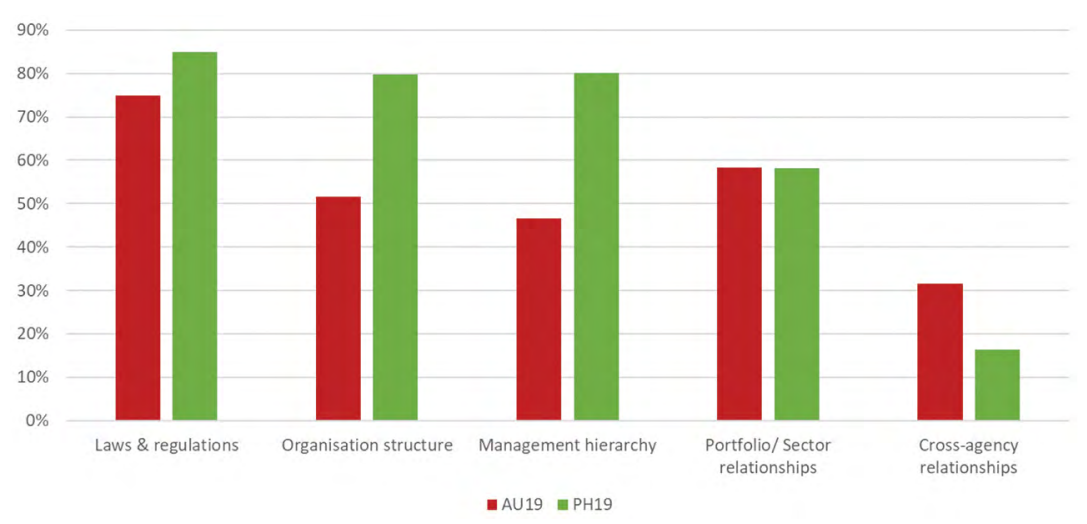

Figure 3.10. Institutional and structural influences on organisational performance management.

Source: Author's summary of study results.

The most important institutional and structural aspects in both countries were laws and regulations. In Australia, the next most important aspect was portfolio and sector relationships. The Australian public sector at the national level is organised by portfolio under the supervision of ministers and department heads. The departments within portfolios have oversight and coordination responsibilities for other organisations assigned to them. The non-departmental organisations are not strictly subsidiaries of the departments of state, but they are required to comply with portfolio regulations and directions, which include coordinated budget planning and reporting. Survey respondents indicated that this has an important influence on their performance management.

The Philippine survey respondents identified organisational structure and management hierarchy as very important influences on performance management, much more important to them than to their Australian counterparts. One reason for this is that staff structures and budgets are more tightly controlled in the Philippines. It is much more difficult to reallocate staff and budgets between organisational units in the Philippines than Australia. This constraint means organisations have to pay more attention to the boundaries of operations because they impose a hard limit on how and where money can be spent and what activities can be performed. The limits on organisational structures and budgets are not necessarily related to the outcomes that organisations are trying to achieve. This is one of the major differences between Australian and Philippine public administration. 
Institutional and structural influence was the highest rated among the six success influences in the Philippines but was the lowest for Australia in the first phase of the study and second lowest for the second phase. It is not clear from this study whether those differences had an impact on the relative effectiveness of performance management. This may be an area for closer examination in future research.

\section{(f) Leadership and management influences}

The importance of effective leadership and management has been a recurring theme in public and private sector management literature. Its importance to the public sector has been given more attention since the emergence and spread of new public management practices in the 1980s. Evidence from the performance management literature (Wright, Moynihan and Pandey 2012) supports the significance of leadership and management and the current study offers further support. Leadership and management was the main influence on performance management identified by Australian respondents and a close second to institutional and structural influence in the Philippine survey.

The survey identified several ways in which leadership and management affected performance management. Chief executive officers (CEOs) and departmental secretaries (who are also ministers in the Philippines) were considered to be the most influential on organisational performance management in both countries, followed by senior executives, ministers and management boards, as shown in Figure 3.11. Government and other external entities ranked lower on the scale of influence in both countries. Middle management and team or unit managers were more important in the Philippines than Australia.

The role of CEOs and secretaries was most evident to respondents through their roles in monitoring results and ensuring that performance information was current and consistent with organisational plans and strategy. They played a less important, though still significant, role in the selection of indicators and targets and provision of feedback on results. Senior management was the most substantial user of performance information in both countries, followed by operational managers. Internal management received more frequent performance reports, usually on a quarterly basis, but sometimes more frequently. 


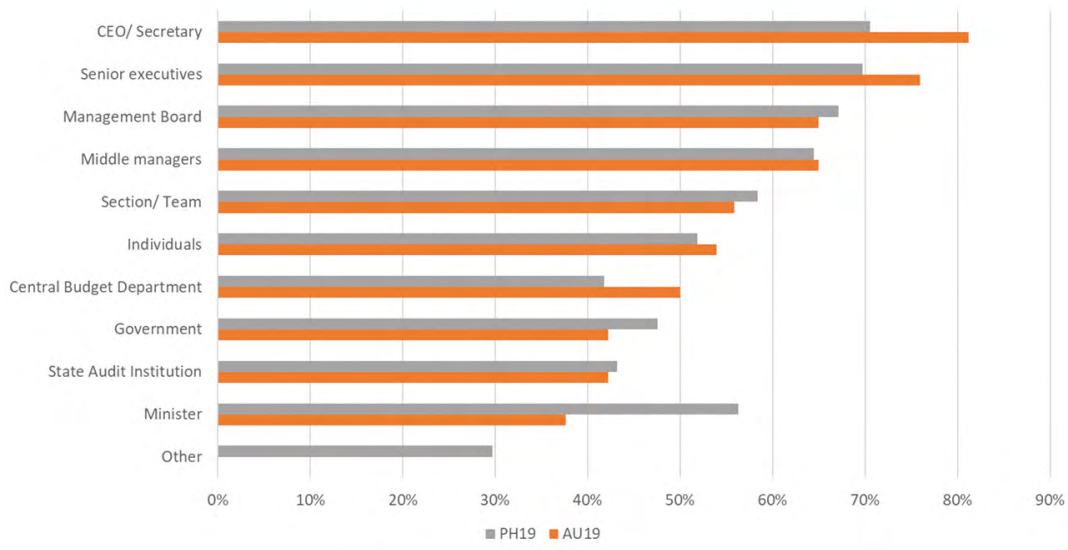

Figure 3.11. Influential people in performance management $(0=$ low, 100 = high).

Source: Author's summary of study results.

Leadership and management was also strongly related to the other five success factors identified in this study, particularly organisational culture and behaviour. In common with other studies, leadership was identified more in a facilitative role, providing direction and encouragement for performance management, rather than in an implementing role. The changes attributed to performance management were often more closely associated with technical, cultural and behavioural influences. Leadership and management were considered to have played important roles in performance-related budget allocation, program revision and priority setting.

\section{(g) Technical influences}

Previous studies, particularly in the professional literature (Schick 2003; World Bank 2005; OECD 2018; Ho, De Jong and Zhao 2019), have noted that a common cause of weaknesses in the quality of performance management is the use of overly complex performance information requirements. Complexity produces challenges for measurement, cost, reporting, interpretation and use of performance information. Countries such as the UK, France, Korea, Netherlands, the US and Canada have all learned the lessons of establishing overly complex performance information arrangements early in the life of their broad-based arrangements. Each of those countries, and others, have refined their systems over time, resulting in fewer, more focused indicators and measures. There is no consensus 
in the literature on what constitutes the best level of complexity for performance information but there is wide acceptance of the view that more is not necessarily better.

In Australia and the Philippines there is considerable variation across organisations but no strong correlation between the size or type of organisation and the complexity of performance data. Figure 3.12 shows that most organisations consider that a set of key performance indicators (KPIs) of between 11 and 50 offers a reasonable balance between the desire for more information and the challenges of maintaining it. The Australian results suggest that, between the two phases of this study, a higher proportion of organisations have concluded that the middle range of complexity examined in this study is appropriate. Figure 3.12 shows that there are around 20 per cent fewer organisations with more than $50 \mathrm{KPIs}$ and 3 per cent fewer organisations with less than $10 \mathrm{KPIs}$ in 2019 compared with 2012.

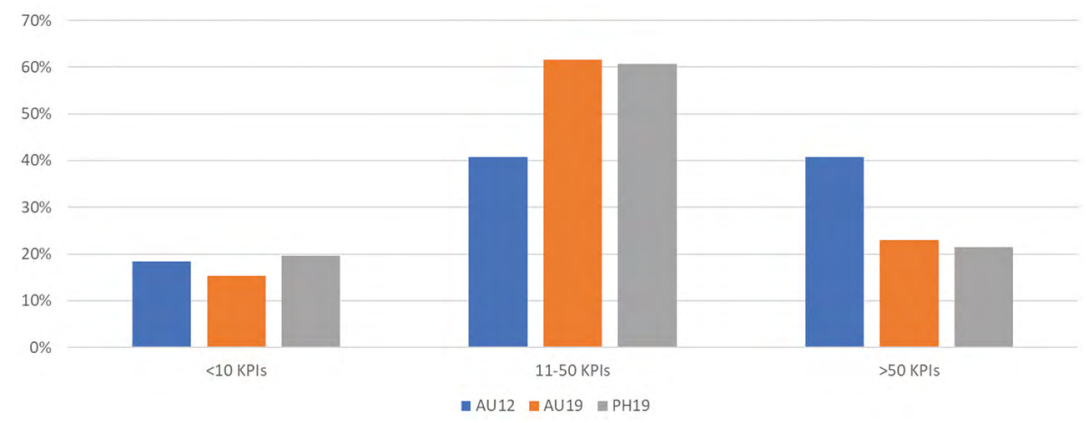

Figure 3.12. Complexity of KPIs.

Source: Author's summary of study results.

It is not clear that complexity is a major distinguishing feature between Australia and the Philippines, and so this would not be expected to be a significant explanation for differences in the quality and use of performance information. This conclusion is supported by attitudes of respondents to the major challenges they are facing in managing performance, as summarised in Figure 3.13. For example, both the Philippine and Australian respondents considered that they only faced moderate challenges in managing performance, which would not have been expected if the level of complexity was problematic. Both countries' respondents identified inconsistent quality, skills, data quality and cost of maintaining the currency of information as among the most significant 
challenges. Australian respondents found budget rigidity to be less of a problem than their Philippine colleagues, which may be related to the more flexible basis for budget appropriations in Australia.

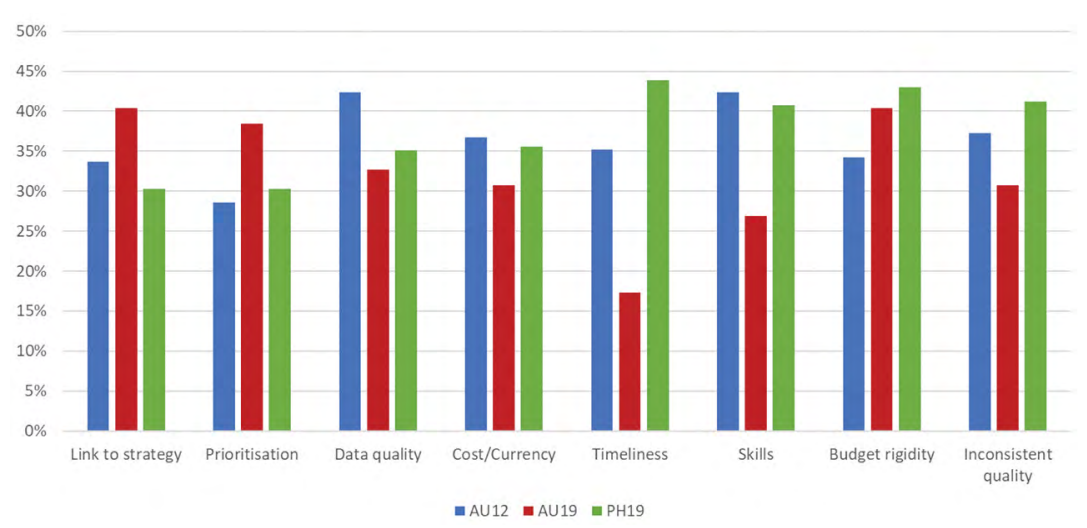

Figure 3.13. Challenges for performance management $(0=$ no challenge, 100 = extremely challenging).

Source: Author's summary of study results.

The Philippine organisations identified timeliness of performance information as its most challenging feature, in contrast to the most recent phase of the Australian study which reported it as least challenging. This could be associated with more frequent reliance on manual recording systems for performance information in the Philippines and less frequent use of special systems or general electronic information systems than Australia, as reported in the survey.

The challenge of skills and capability to produce consistent quality through performance management has been addressed differently in the two countries. In 2012, Australian respondents relied to a greater extent on internal guidance and less on support from central finance and audit institutions. This was different for respondents to the 2019 Australian questionnaire, where central finance and audit institutions were more important than internal sources. This may have been related to the increase in guidance and support provided by DOF following implementation of the PGPA Act in 2013. Philippine respondents relied most heavily on the Department of Budget and Management (DBM) while still drawing on guidance from state audit (COA) and internal sources. 
The importance of performance dialogue and analysis of results is evident in the use of data collection and reporting at multiple levels within organisations in both countries. Philippine organisations use management and planning units within organisations more extensively and Australia has relied more on central finance and budgeting units. Both have also collected data at service delivery level and neither have relied on external contractors to collect and manage performance data to a significant extent.

Both countries produce performance reports for different groups of stakeholders, more frequently (monthly or quarterly) for internal stakeholders within operating units and senior management, and less frequently (often yearly) for external stakeholders. The Philippine respondents provided more frequent reports to elected or politically appointed officials than Australia. This could reflect the more extensive involvement of elected or politically appointed officials in the operations of organisations in the Philippine system than the Westminster-style separation between elected and career officials in the Australian administration.

\section{(h) Cultural influences}

Understanding and interpreting organisational culture is a challenging undertaking. Identifying its influence on performance management adds another level of complexity, but one that is increasingly being seen as important for public sector organisations (Ginevičius and Vaitkūnaite 2006; Woolcock 2014). The Australian Public Service Commission placed strong emphasis on organisational culture in its recent report on performance management (APSC 2019).

Respondents in both countries identified organisational culture as one of the most important influences on their performance management. The first aspect of culture examined by this study was the overall attitude of organisations to performance management. Respondents were asked to identify what they thought people in their organisations considered to be the main purpose(s) of performance management. In both countries compliance with government requirements and improving organisational processes were identified as the top two purposes. Improvement of results and providing a better understanding of organisational performance were considered to be less important purposes but still significant, as shown in Figure 3.14. 


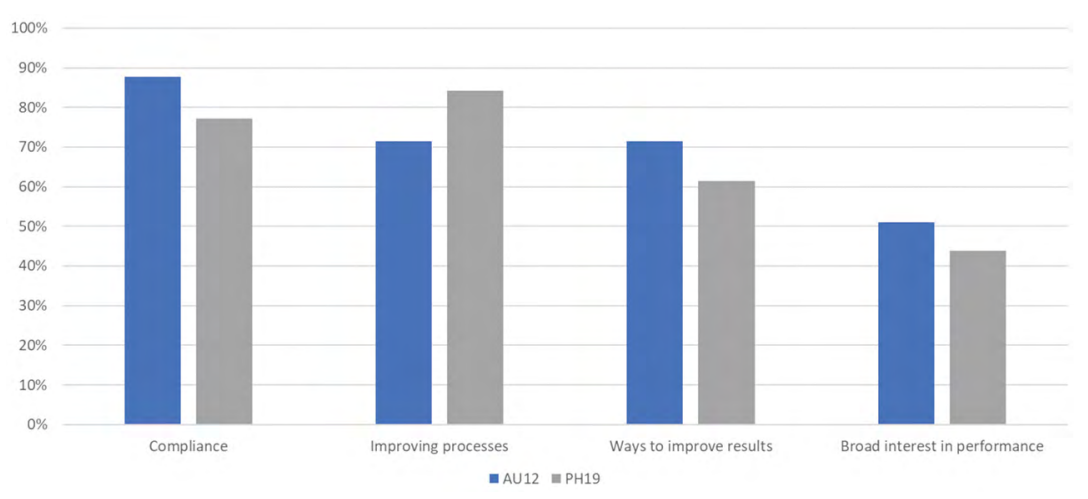

Figure 3.14. Purpose of performance management practices (\% of respondents).

Source: Author's summary of study results.

Figure 3.14 suggests that respondents have a more functional view of performance management: that it is intended to address immediate needs and operational efficiency, rather than more fundamental considerations of effectiveness and impact. This is consistent with findings on Australian government organisations by Wanna and Podger (2017). This may have been influenced by the positions held by respondents to the survey, most of whom were in central areas of their organisations rather than service or program delivery areas. It could be examined in future work by obtaining multiple responses from within organisations from people with different perspectives and responsibilities.

The second aspect of culture examined by this study was to identify the ways in which organisations operated, along the lines of work by Hofstede, Hofstede and Minkov (2010). Participants were asked about the features of culture in their organisation, aimed at identifying the extent to which they demonstrated qualities such as dynamism, adaptability, flexibility, loyalty and commitment, and being hierarchical or open to new ideas and ways of working. The survey results, summarised in Figure 3.15, indicate that loyalty to the organisation is a major factor for staff in both countries. This is consistent with other studies that have found public service workers to be highly motivated by public service ideals, goals and objectives rather than individualistic or financial goals (Taylor 2013; Rasul, Rogger and Williams 2018). 


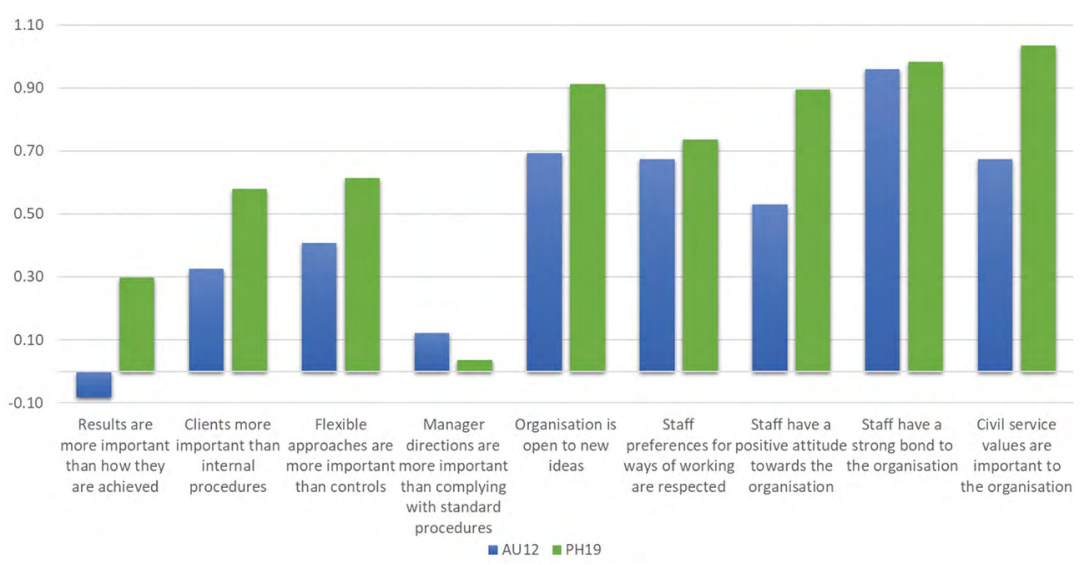

Figure 3.15. Attributes of organisational culture $(2=$ strongly agree, 0 = neutral, $-\mathbf{2}$ = strongly disagree).

Source: Author's summary of study results.

The study found that staff in both countries tended to place significant emphasis on procedures, processes and controls, which moderated their preparedness to be flexible and results-driven. This is also consistent with other studies and the conventional Weberian concepts of public administration, which emphasise the importance of orderly, well-defined practices and procedures as a foundation for effective operations.

The pattern of results relating to organisational culture was similar for both countries, although the Philippine organisations scored more positively on all aspects, particularly in relation to loyalty to civil service values, their organisation and its leadership.

\section{(i) Behavioural influences}

The work of Smith (1995), Bevan and Hood (2005), Radin (2006) and others has provided convincing evidence of the strong, often disastrous, behavioural responses to performance targets in the public sector. When incentives, either positive or negative, are sufficient to influence behaviour, individuals and organisations will respond with attempts to meet the requirements, including through gaming, narrowing their focus to what is measured or, in extreme cases, falsifying reports. 
The analysis of behaviour in this study focused more on the consequences of behaviour for organisational performance rather than the behaviour per se. On the positive side, it identified the incentives and encouragement to improve performance by individuals and organisations. On the negative side, it examined the sensitivity of organisations to criticism of performance as an incentive to avoid disappointing or controversial results. Comparing those responses with the effects and impacts of performance management was expected to provide an indication of whether behaviour was positively or negatively affecting success, and the strength of its influence.

This is one aspect where Australia and the Philippines have significantly different practices in relation to performance management, as illustrated in Figure 3.16. The Philippines Government provides annual financial incentives to organisations and their staff for meeting agreed targets. The financial rewards for individuals amounted to over 15 per cent of annual salary for more than half of the Philippine respondents. In 2012 some Australian organisations provided financial rewards for outstanding performance but were usually less than 5 per cent of salary and were not available to all staff. In 2019, none of the Australian respondents reported offering financial rewards for performance.

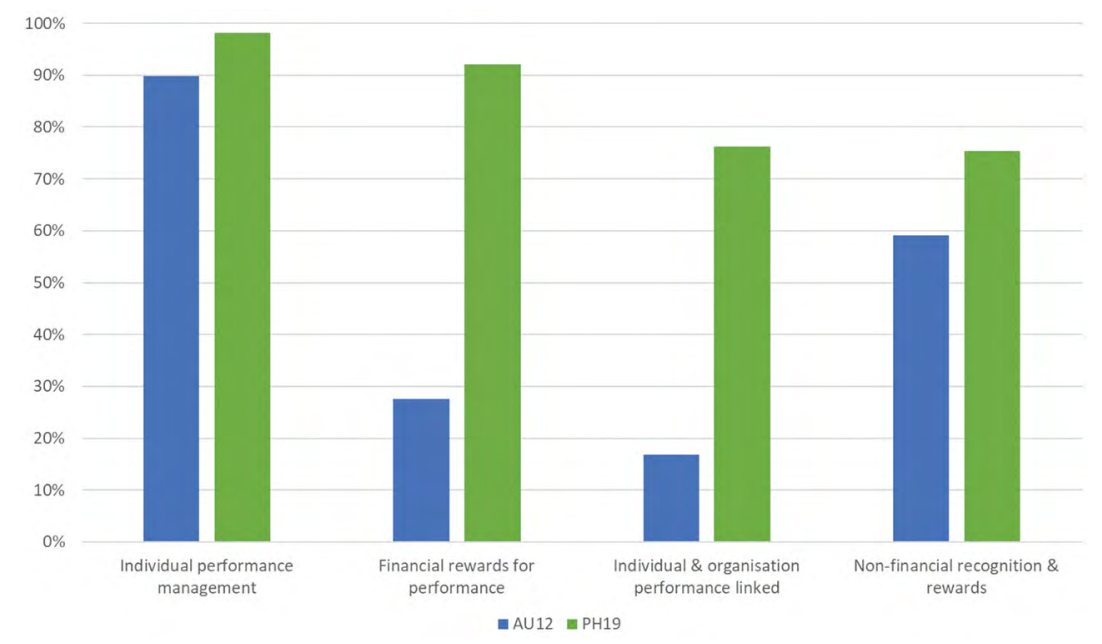

Figure 3.16. Performance incentives.

Source: Author's summary of study results. 
Individual performance management practices were applied in both countries and both offered non-financial rewards and recognition for good performance. In the Philippines, the most widely used scheme mentioned by respondents was the Program on Awards and Incentives for Service Excellence (PRAISE). Australian organisations mentioned a variety of awards, including organisation-specific schemes and Australia Day awards used across the public service.

The survey results did not indicate a strong and systematic relationship between performance improvement and provision of financial rewards linked to organisational performance in the Philippines. The correlation between financial and non-financial rewards and performance improvements was close to zero for both countries. The correlation was even slightly negative between financial rewards and staff motivation and personnel evaluation results. The relationship was more positive between financial rewards and the quality of performance measures. The significance of these relationships should be treated with caution, however, considering the broad rating categories used for this study. More precise analysis would need to be performed to achieve a better understanding of the relationships.

Examination of the response to criticism focused on the main external influences on organisations, as shown in Figure 3.17. Philippine respondents were most responsive to DBM and COA while Australian respondents were more responsive to criticism by their minister and parliament. The Philippine results may have been affected by the financial performance scheme because both DBM and COA have important roles to play in deciding on whether organisations satisfy the requirements for rewards. The monitoring of organisational performance by the Australian DOF is less intensive, and oversight of performance by the Australian National Audit Office is limited to performance audits and assessment of organisational performance management arrangements. 


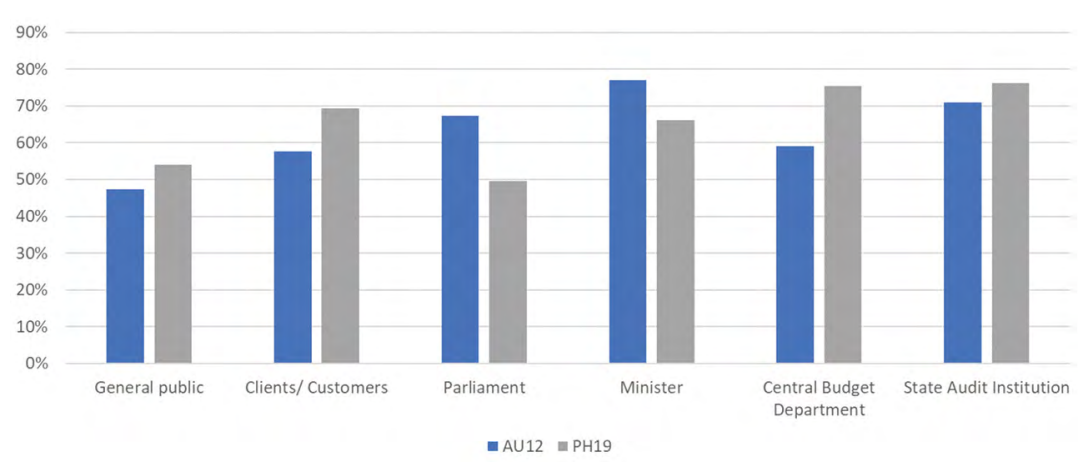

Figure 3.17. Response to criticism ( $0=$ no response, $100=$ strong response).

Source: Author's summary of study results.

The response to criticism was only weakly related to performance improvements but, as with positive incentives, it was more closely related to the quality of performance information. Sensitivity to criticism from central budget departments and state audit institutions was most strongly related to quality improvements. The stronger influence of central agency criticism on quality is understandable because they are more likely to include technical matters in any comments about performance than other stakeholders.

\section{(j) Individual organisation results}

Much of the emphasis in this paper has been on the aggregate or average results in both countries. It would be too time- and space-consuming to report findings in relation to each of the organisations, so the discussion has been limited to higher-level attributes. In fact, the variation of results within each of the countries was greater than the differences between aggregated country scores. One question that was important for this research was whether the aggregate findings were consistent at the individual organisation level. The study undertook an in-depth sample analysis of 20 per cent of highest and lowest scores on the six influences referred to in the central hypothesis. Their scores on quality, use and impact were reviewed in detail along with other survey data to determine whether there was consistency in results across all aspects.

The sample analysis showed that each organisation that achieved low scores on a majority of the six influences also had low scores on quality, use and impact questions. It also showed that organisations with high scores 
on most of the six influences had high scores on quality, use and impact. The impact scores were less consistently related to the six influences than quality and use. This is not surprising considering that many other factors affect an organisation's impact, many of which are outside their control. This would alter the extent to which performance management alone could achieve an impact.

One strong feature of the sample analysis that warrants specific mention is the strong correlation between performance information use by management and ministers and the effects (coefficient $=0.74$ ) and impacts achieved (coefficient $=0.67$ ). This finding reinforces a key theme within the literature that use of performance information is crucial to the value of performance management arrangements (Moynihan 2008). Simply producing high-quality information is not sufficient; it has to be used to achieve any benefit. Culture and behaviour, followed by leadership and management, were the most important success factors associated with use of performance information in the detailed sample analysis.

\section{Conclusions}

The study presented in this paper sought to identify the main influences on success of performance management in public sector organisations. It found strong support for the proposition that there are six main influences encompassing external, institutional and structural, leadership and management, technical, cultural and behavioural factors. Organisations responding to the survey from the Philippines and Australia considered that all six influences were important, and no other influences were identified.

The importance of the six influences was supported by indications that the improvements directly attributable to performance management showed strong relationships with the extent of improvements. When the influences were stronger, performance improvement was stronger. When the influences were weak, very little performance improvement was identified by respondents. The most important influence on performance management in the Philippines was institutional and structural aspects. These included laws, regulations and organisational structure as the most important elements. Leadership and management was also very important in the Philippines and was most important for Australian respondents. The main characteristics of leadership and management that were noted 
by survey respondents were the involvement of senior management in monitoring performance and ensuring it was up to date and aligned with organisational strategy.

The study found that senior management was the main user of performance reports in both countries. The survey showed that stronger usage by senior management and ministers was correlated with higher levels of performance improvement across a variety of attributes including staff focus on results, internal processes, service delivery, program improvement and budget allocation. The six influences were strongly correlated with the quality and use of performance information, especially culture, behaviour, leadership and management. The six influences were less closely related to improvements and impacts of performance management, but the study did not filter out the effects of other influences on results, some of which would be outside of each organisation's control.

There are strong parallels between the findings of this study and previous works. In relation to this volume, it is particularly relevant to highlight the parallels with John Wanna's oeuvre. John has consistently identified the importance of performance management at the organisational level and shown how it has influenced the quality of performance information and performance results (Wanna, O'Faircheallaigh and Weller 1999; Hawke and Wanna 2010; Podger et al. 2018). He has highlighted the potential for performance information to be a political tool and has noted the differential ways in which it has been used across governments and in different periods and contexts (Wanna, Jensen and de Vries 2010). An important feature of John's work has been to identify the complexity of incentives and influences on performance management for the various groups of stakeholders, including politicians, ministers, central finance agencies, service delivery organisations and other government bodies. He has also emphasised the important roles of different technologies and processes, and the potential for citizens to actively participate in design, implementation and monitoring of public services (Lindquist, Vincent and Wanna 2013).

There are limitations of the approach taken in this study which should be considered when interpreting the findings. The main limitations relate to the selection of two countries with long experience in performance management and the data collection method. The results may be stronger for Australia and the Philippines because they have a long tradition of including performance information in their planning and management. 
The results may not be so clearly positive in countries with less experience or less positive experiences with performance management. The use of a single respondent for each organisation places heavy reliance on that individual having a sound knowledge of performance management and how it affects the organisation. A wider sample of individuals within organisations may have provided a more varied picture. Self-reported performance without robust validation should be treated with caution. It is more likely to be subject to optimism bias, particularly where it reflects on the quality or performance of the respondents or their organisations, as is the case for this study.

In consideration of these limitations, the researcher has sought to mitigate the risks by including two countries to provide some measure of crossreference. The individuals selected for responses to the survey were carefully chosen as the most knowledgeable about the arrangements in each organisation, with assistance from the central budget department in each country (though the departments were not involved in distributing, collecting or analysing the questionnaires and were not involved in interviews). Interviews were undertaken to confirm and validate responses from a large, targeted sample of respondents. Ultimately the robustness of the analysis will be strengthened by additional work in the two countries covered by the study and other countries using the same, or improved, methodology. Those options will be considered at the end of this study and may be taken up by other researchers as well.

The results of this study are encouraging, as they have supported the basic hypothesis and have supported findings from previous research and confirmed six influences on success of performance management in public sector organisations, and only six. This provides a firmer foundation for further research within and between those six areas to strengthen and deepen understanding of how they influence and how they can be used to improve performance management.

\section{References}

Australian Public Service Commission (APSC). 2019. Performance Management in the APS. Canberra: Commonwealth of Australia.

Behn, R. D. 2003. 'Why measure performance? Different purposes require different measures'. Public Administration Review 63(5): 586-606. doi.org/10.1111/ 1540-6210.00322. 
Bevan, C. and C. Hood. 2005. What's Measured is What Matters: Targets and Gaming in the English Public Health Care System. Discussion paper no. 501. Public Services Programme, Economic and Social Research Council, UK.

Bohte, J. and K. Meier. 2001. 'Structure and the performance of public organizations: Task difficulty and span of control'. Public Organization Review 1 (September): 341-354.

Curristine, T. and S. Flynn. 2013. 'In search of results: Strengthening public sector performance'. In M. Cangiano, T. Curristine and M. Lazare (eds) Public Financial Management and its Emerging Architecture. Washington DC: International Monetary Fund.

De Waal, A. A. 2010. 'Performance-driven behavior as the key to improved organizational performance'. Measuring Business Excellence 14(1): 79-95. doi.org/10.1108/13683041011027472.

Department of Budget and Management (Philippines). 2016. Program Expenditure Classification: The Next Phase of the Performance-Informed Budget. Manila: Government of the Philippines.

Department of Finance (Australia). 2016. Overview of the Enhanced Commonwealth Performance Framework. Resource Management Guide no. 130. Canberra: Commonwealth of Australia.

Dull, M. 2008. 'Results-model reform leadership: Questions of credible commitment'. Journal of Public Administration Research and Theory 19(2): 255-284. doi.org/10.1093/jopart/mum043.

Fritz, V., M. Verhoeven and A. Avenia. 2017. Political Economy of Public Financial Management Reforms: Experiences and Implications for Dialogue and Operational Engagement. Washington DC: World Bank.

Gao, J. 2015. 'Performance measurement and management in the public sector: Some lessons from research evidence'. Public Administration and Development 35: 86-95. doi.org/10.1002/pad.1704.

Ginevičius, R. and V. Vaitkūnaite. 2006. 'Analysis of organizational culture dimensions impacting performance'. Journal of Business Economics and Management 7(4): 201-211. doi.org/10.3846/16111699.2006.9636141.

Hawke, L. R. 2012. 'Australian public sector performance management: Success or stagnation?' International Journal of Productivity and Performance Management 61(3): 310-328. doi.org/10.1108/17410401211205669. 
Hawke, L. R. and J. Wanna. 2010. 'Australia after budgetary reform: A lapsed pioneer or decorative architect?' In J. Wanna, L. Jensen and J. de Vries (eds) The Reality of Budgetary Reform in OECD Nations: Trajectories and Consequences. Cheltenham, UK: Edward Elgar. doi.org/10.4337/9781849805636.00010.

Ho, A. T., M. De Jong and Z. Zhao. 2019. Performance Budgeting Reforms: Theories and International Practices. New York: Routledge.

Hofstede, G., G. J. Hofstede and M. Minkov. 2010. Cultures and Organizations: Software of the Mind. 3rd edition. McGraw Hill.

Hood, C. 2006. 'Gaming in targetworld: The targets approach to managing British public services'. Public Administration Review 66(4): 515-521. doi.org/ 10.1111/j.1540-6210.2006.00612.x.

Hood, C. 2012. 'Public management by numbers as a performance-enhancing drug: Two hypotheses'. Public Administration Review 72(1): S85-S92. doi.org/ 10.1111/j.1540-6210.2012.02634.x.

International Monetary Fund (IMF). 2014. Government Finance Statistics Manual 2014. Washington DC: International Monetary Fund.

Kroll, A. 2015a. 'Drivers of performance information use: Systematic literature review and directions for future research'. Public Performance \& Management Review 38(3): 459-486. doi.org/10.1080/15309576.2015.1006469.

Kroll, A. 2015b. 'Exploring the link between performance information use and organizational performance: A contingency approach'. Public Performance \& Management Review 39(1): 7-32. doi.org/10.1080/15309576.2016.1071159.

Lindquist, E., S. Vincent and J. Wanna (eds). 2013. Putting Citizens First: Engagement in Policy and Service Delivery for the 21st Century. Canberra: ANU E Press. doi.org/10.22459/PCF.08.2013.

Management Advisory Committee (MAC). 2001. Performance Management in the Australian Public Service: A Strategic Framework. Canberra: Commonwealth of Australia.

Moreno, R. and M. Garza. 2015. Public Participation and Change: Three Cases where CSOs used Public Participation to Advance Fiscal Transparency in Mexico. Global Initiative for Fiscal Transparency. Available at: www.fiscaltransparency. net/resourcesfiles/files/20151015135.pdf.

Moynihan, D. P. 2008. The Dynamics of Performance Management: Constructing Information and Reform. Washington DC: Georgetown University Press. 
Moynihan, D. P. and I. Beazley. 2016. Towards Next-Generation Performance Budgeting: Lessons from the Experience of Seven Reforming Countries. Washington DC: World Bank. doi.org/10.1596/978-1-4648-0954-5.

Moynihan, D. P. and S. K. Pandey. 2010. 'The big question for performance management: Why do managers use performance information?' Journal of Public Administration Research and Theory 20(March): 849-866. doi.org/ 10.1093/jopart/muq004.

Mussari, R., A. E. Tranfaglia, C. Reichard, H. Bjorna, V. Nakarosis and S. Bankauskaite-Grigaliuniene. 2016. 'Design, trajectories of reform and implementation of performance budgeting in local governments: A comparative study of Germany, Italy, Lithuania and Norway'. In S. Kuhlmann and G. Bouckaert (eds) Local Public Sector Reforms in Times of Crisis. London: Palgrave Macmillan. doi.org/10.1057/978-1-137-52548-2_6.

Nicholl, P. 2006. 'Organisational structures do matter for good governance and good performance'. Comparative Economic Studies 48: 214-228. doi.org/ 10.1057/palgrave.ces.8100166.

Organisation for Economic Cooperation and Development (OECD). 2018. OECD Best Practices for Performance Budgeting. GOV/PGC/SBO(2018)7. OECD Public Governance Directorate, Public Governance Committee.

Organisation for Economic Cooperation and Development (OECD). 2019. Budgeting and Public Expenditures in OECD Countries 2019. Paris: OECD Publishing. doi.org/10.1787/8b33361e-en.

Podger, A., T. Su, J. Wanna, H. S. Chan and M. Niu (eds). 2018. Value For Money: Budget and Financial Management Reform in the People's Republic of China, Taiwan and Australia. Canberra: ANU Press. doi.org/10.22459/vm.01.2018.

Radin, B. A. 2006. Challenging the Performance Movement: Accountability, Complexity, and Democratic Values. Washington DC: Georgetown University Press.

Rasul, I., D. Rogger and M. Williams. 2018. Management and Bureaucratic Effectiveness. Policy research working paper 8595. Washington DC: World Bank.

Robinson, M. and J. Brumby. 2005. Does Performance Budgeting Work? An Analytical Review of the Empirical Literature. IMF Working Paper WP/05/210. International Monetary Fund. doi.org/10.5089/9781451862294.001. 
Santiso, C. 2015. 'Why budget accountability fails? The elusive link between parliaments and audit agencies in the oversight of the budget'. Brazilian Journal of Political Economy 35(3): 601-621. doi.org/10.1590/0101-31572015 v35n03a12.

Schick, A. 2003. 'The performing state: Reflection on an idea whose time has come but whose implementation has not'. OECD Journal on Budgeting 3(1): 71-103. doi.org/10.1787/budget-v3-art10-en.

Schick, A. 2014. 'The metamorphoses of performance budgeting'. OECD Journal on Budgeting 13(2): 49-79. doi.org/10.1787/budget-13-5jz2jw9szgs8.

Smith, P. 1995. 'On the unintended consequences of publishing performance data in the public sector'. International Journal of Public Administration 18: 277-310. doi.org/10.1080/01900699508525011.

Talbot, C. 2010. Theories of Performance: Organizational and Service Improvement in the Public Domain. Oxford: Oxford University Press.

Taylor, J. 2011. 'Factors influencing the use of performance information for decision making in Australian state agencies'. Public Administration 89(4): 1316-1334. doi.org/10.1111/j.1467-9299.2011.02008.x.

Taylor, J. 2013. 'Goal setting in the Australian Public Service: Effects on psychological empowerment and organizational citizenship behavior'. Public Administration Review 73(3): 453-464. doi.org/10.1111/puar.12040.

Venner, M. 2019. 'The long history of performance budgeting in the Philippines'. In A. T. Ho, M. De Jong and Z. Zhao (eds) Performance Budgeting Reforms: Theories and International Practices. New York: Routledge. doi.org/10.4324/ 9781351055307-8.

Wanna, J., J. Forster and J. Kelly. (2000) 2003. Managing Public Expenditure in Australia. St Leonards: Allen \& Unwin.

Wanna, J., L. Jensen and J. de Vries. 2003. Controlling Public Expenditure: The Changing Roles of Central Budget Agencies - Better Guardians? Cheltenham, UK: Edward Elgar.

Wanna, J., L. Jensen and J. de Vries. 2010. The Reality of Budgetary Reform in OECD Nations: Trajectories and Consequences. Cheltenham, UK: Edward Elgar. doi.org/10.4337/9781849805636.

Wanna, J., C. O’Faircheallaigh and P. M. Weller. (1992) 1999. Public Sector Management in Australia. South Melbourne: Macmillan. 
Wanna, J. and A. Podger. 2017. 'Submission to the independent review of the PGPA Act'. Canberra: Parliament of Australia.

Woolcock, M. 2014. Culture, Politics and Development. World Bank Policy Research Working Paper No. 6939. Washington DC: World Bank.

World Bank. 2005. Public Financial Management Performance Measurement Framework. Public Expenditure and Financial Accountability Secretariat, Washington DC: World Bank.

Wright, B. E., D. P. Moynihan and S. K. Pandey. 2012. 'Pulling the levers: Transformational leadership, public service motivation and mission valence'. Public Administration Review 72: 206-215. doi.org/10.1111/j.1540-6210. 2011.02496.x. 
This text is taken from Politics, Policy and Public Administration in Theory and Practice: Essays in Honour of Professor John Wanna, edited by Andrew Podger, Michael de Percy and Sam Vincent, published 2021 by ANU Press, The Australian National University, Canberra, Australia.

doi.org/10.22459/PPPATP.2021.03 